\title{
SMALL SCALE GENERATION BY HARNESSING THE WIND ENERGY
}

\author{
R.D.Bhagat ${ }^{1}$, M.S.Lande ${ }^{2}$ \\ ${ }^{1,2}$ Assistant professor, College of Engineering \& Technology Akola Santa Gadge Baba Amravati University
}

\begin{abstract}
Generating electricity from wind has been centered around the rotation rotating windmill in which rotating shaft coupled to the generator used to generate electricity. Other sources such as solar power hydropower, thermal power, wind power are used for generating electricity in kilo watts and megawatt but there is no such kind of application which can generate electricity on sub 100 watt scale. So as to generate electricity on small scale and to provide cheap source of energy for lighting the houses in remote where there is no other sources are available. And to generate a power source that can be constructed with the help of local material and if problem occurs that can be fixed by the local people. About $2 \%$ of global electricity production comes from wind-powered generators. Their capacity has doubled in the past few years. In some countries it is more popular than solar energy because it is cheaper on a cost per watt basis. However, for powering small devices there has been minimal activity to harvest energy from the wind. This is because conventional electromagnetic wind turbines require rotating fins and gearing which adds bulk, and they become less efficient when scaled down.
\end{abstract}

Key Words: Harnessing, Wind Energy, Rotating Shaft

\section{INTRODUCTION}

When more research is done on shrinking the size of the windmill it was found that there is lot of friction in the gearboxes which does not permit us to do that. Also when research is done in order to shrink the size of the turbine it is found that they are not at all efficient on small scale also there is need to make such kind of generator which can be manufactured by local people by using local material and if any problem occur it can be fixed by local people.

Small scale generators harnessing the wind energy is used for generating electricity on small scale and cheaper cost. The small scale generator harnessing wind energy uses the local material. Its working principle based on the aero elastic flutter and electromagnetic induction. Whenever the wind blows across the membrane the membrane oscillate and there is relative change in position of magnet with respect to the coil and thus result in induced emf and thus the electricity is generated. The small scale generator can be connected in series in order to enhance the power output.

\subsection{Significance of the Topic}

- Small scale generator harnessing wind energy has no gearing or bearing, making it more efficient than scaled down wind turbine which have friction. In addition due to nature of aero elastic flutter, small scale generator can be turned to optimize their output at different wind speed and therefore are not dependent on high wind speed.
- Small scale generator has ability to run radios, power transmission from wireless sensor, charge cell phone and can be use for LED lights.

\subsection{Objective of Work}

Throughout the world today there is huge amount of pressure on countries to reduce the carbon emission and use renewable energy instead of energy attained though fossil fuel. Alternative ways of producing electricity nowadays are being researched more than ever.

- Reduce the reliance on petrol and diesel and to move into a renewable energy based future this will reduce the green house gases emission significantly.

- We aim to provide the community with a way to harness the energy for much smaller amount of money. There will not be any continuous payment that has to be made.

- Renewable energy is increasingly being utilised in place of non renewable energy such as that attained from fossil fuel and to provide community with electricity that they can use for small appliances and basic necessities. The use of renewable energy is cheaper cleaner and much better for environment.

- Achieving the greater access to power by providing families with their own ways of getting power without reliance on any other clients. This will make it cheaper more readily available.

In order to attain the objective of generating the electricity at cheaper rate we are using two fundamental principles

- Aeroeleastic flutter from wind

- Electromagnetic induction 
Aero elastic flutter involves the aerodynamics forces on structure which results in a self feeding high energy oscillation. Flutter has the potential to occur in any object subjected to the wind condition. When the natural frequency of the membrane or tape becomes equal to resonance frequency flutter occurs.

Aero elastic flutter result in self exciting oscillation and will build up until the aerodynamics or mechanical damping of the system matches the energy input.

The second principle behind the small scale energy generation by harnessing wind energy is use of electromagnetic induction. Electromagnetic induction is the production of voltage across the conductor in changing magnetic field. Faraday found that and stated that the induced electromotive force or EMF in any closed circuit is equal to the time rate of change of magnetic flux.

$$
\epsilon=-N \frac{d \Phi}{d t}
$$

Where $\mathrm{N}$ is the number of loops of conductive coil $d \Phi$ is the change in electromagnetic flux

In practice changing magnetic field is applied through a conductive wire in a closed circuit will generate electricity. The current produced is the alternating current with frequency typically in between 50 to $60 \mathrm{~Hz}$. Depending on the wind speed and the construction dimension for the unit. One more principle that needs to be mention is the effective process of converting the generated alternating current into direct current. To change the $\mathrm{AC}$ into $\mathrm{DC}$ we need a rectifier. A rectifier is a electrical device that convert the alternating current to direct current suitable for trickle charging a lead acid battery. The simplest rectifiers are made from a single diode. The diode works by blocking either the negative or positive portion of the input wave to leave just a current. The rectifier becomes more advance with multiple diodes and bridges to smooth the output current and convert both positive and negative polarity input current. The end result produces a smoother more efficient conversion to direct current.

\section{COMPONENTS USED IN SMALL SCALE GENERATOR HARNESSING WIND ENERGY}

\subsection{Support Structure}

The bracket holds together the entire unit. It can be fabricated from available material such as timber, aluminium or plastic. The bracket requires a top and bottom piece and four spacer pieces. It is important to consider the lifespan of the material since exposure to the element is imminent.

The dimension of the wooden structure is $=1 \mathrm{~m} \times 12 \mathrm{~mm} \times$ $12 \mathrm{~cm}$

\subsection{Copper Coil}

The copper coil provides the medium for electromagnetic induction. According to faraday law of electromagnetic induction the induced electromotive force is directly proportional to number of turns of coil N. In order to reduce the cost involve we can use electronic waste the copper coils available in appliance such as television and speaker.

The number of turns for coil which we are using is 200 on each coil of gauge 25 .

\subsection{Ribbon or Membrane}

The ribbon or membrane may take as video tape in order to reduce the cost involve. The membrane when exposed to wind will experience the aero elastic flutter. Wind will cause the ribbon to move up and down with high frequency oscillating motion. The ribbon must be torsionally strong so that the oscillations are as linear as possible.

\subsection{Magnet}

Two magnets are attached to the membrane in line with centre of copper coil. Stronger the magnetic field greater the magnetic flux and thus the larger induced current. As the magnet move up and down with the flutter the polarity of the field through the copper coil reverse.

The magnet used is having the strength of magnetic field of 1.5 Tesla.

\subsection{Power Conditioning Circuit}

Power conditioning circuit uses the series of connection to achieve higher voltages for low wind speed. The circuit uses rectifier, a smoothing capacitor a step up supply and a power storage device such as rechargeable battery or a super capacitor. The function of rectifier is and capacitor is to convert the output of the coils, which is in the form of alternating current, into smooth direct current. The dc current is then fed into the step up supply, or a device storage device is provided to buffer between the current drawn by the application and the supply from the coils of the generator. Therefore there is requirement of diode in the circuit board to control flow of current. 


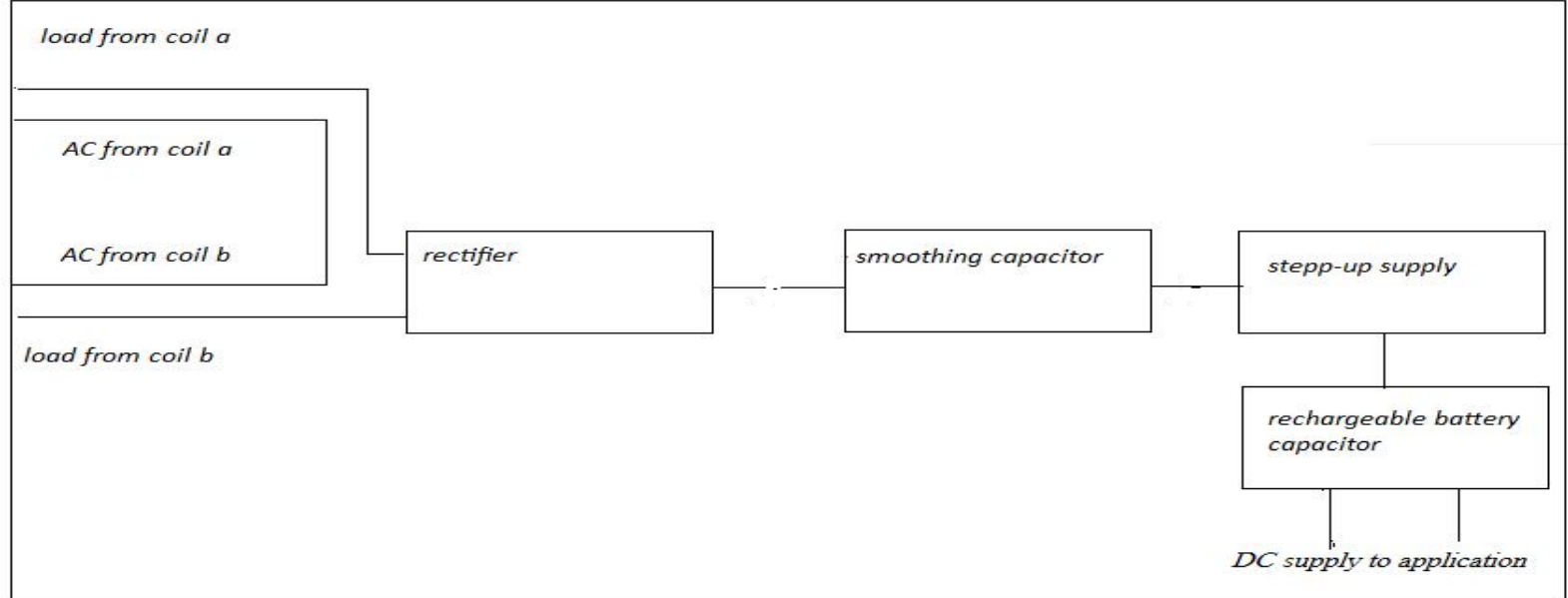

Fig 1 showing the power conditioning circuit for small scale energy generator harnessing wind energy

Table 1 part specification for small scale generator harnessing the wind energy

\begin{tabular}{|c|c|c|}
\hline Name & Specification & Quantity \\
\hline Ribbon or membrane & $1 \mathrm{~m} \times 1 \mathrm{~mm} \times 3.5 \mathrm{~cm}$ & 4 \\
\hline Rare earth Magnet & Strength 1.5 Tesla & 4 \\
\hline Copper coil & 25 gauge, 200 turns & 2 \\
\hline Wooden sheet & $1 \mathrm{~m} \times 12 \mathrm{~mm} \times 12 \mathrm{~cm}$ & 4 \\
\hline Spacer & $12 \mathrm{~cm} \times 12 \mathrm{~mm}$ & 4 \\
\hline
\end{tabular}

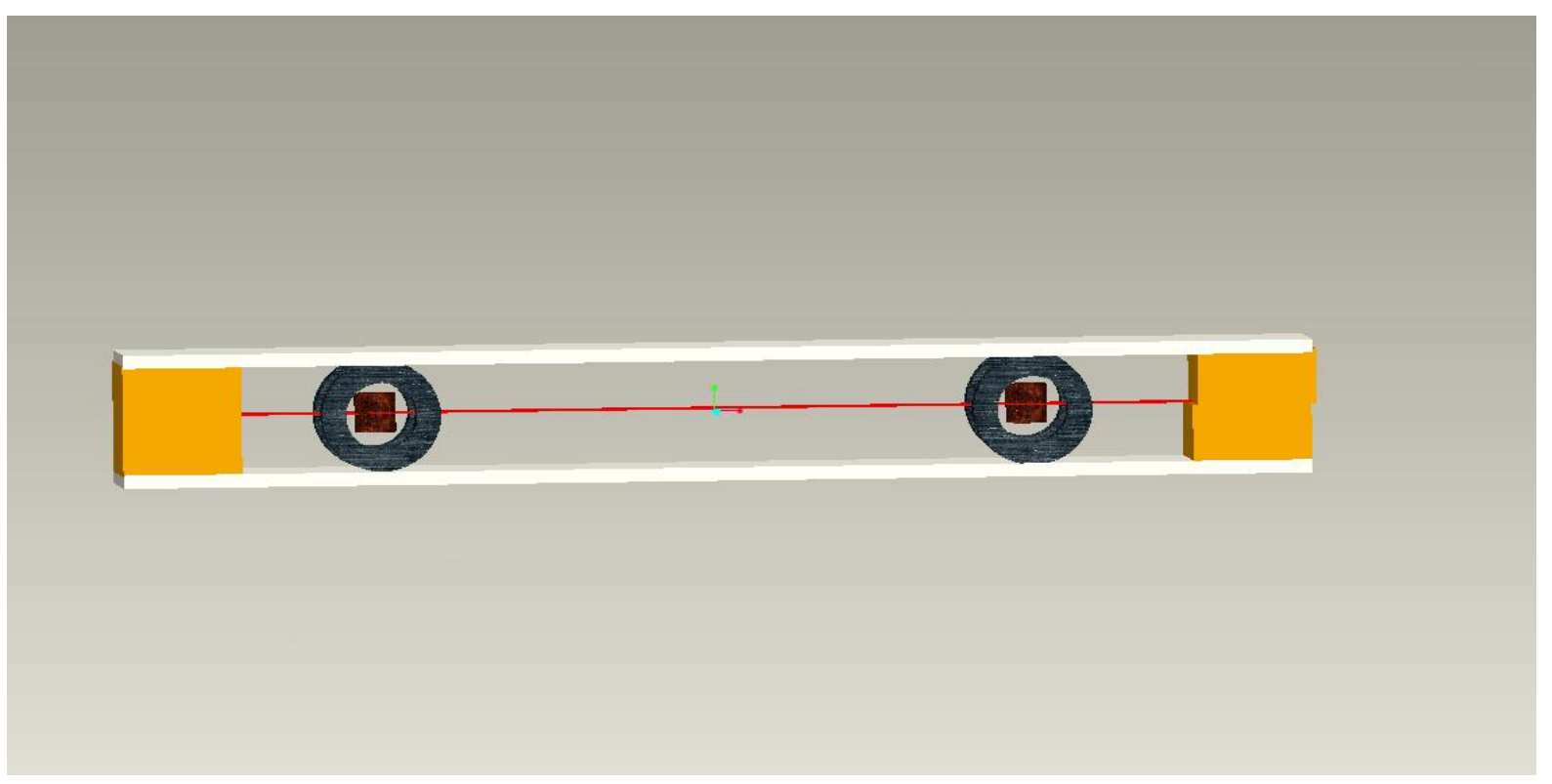



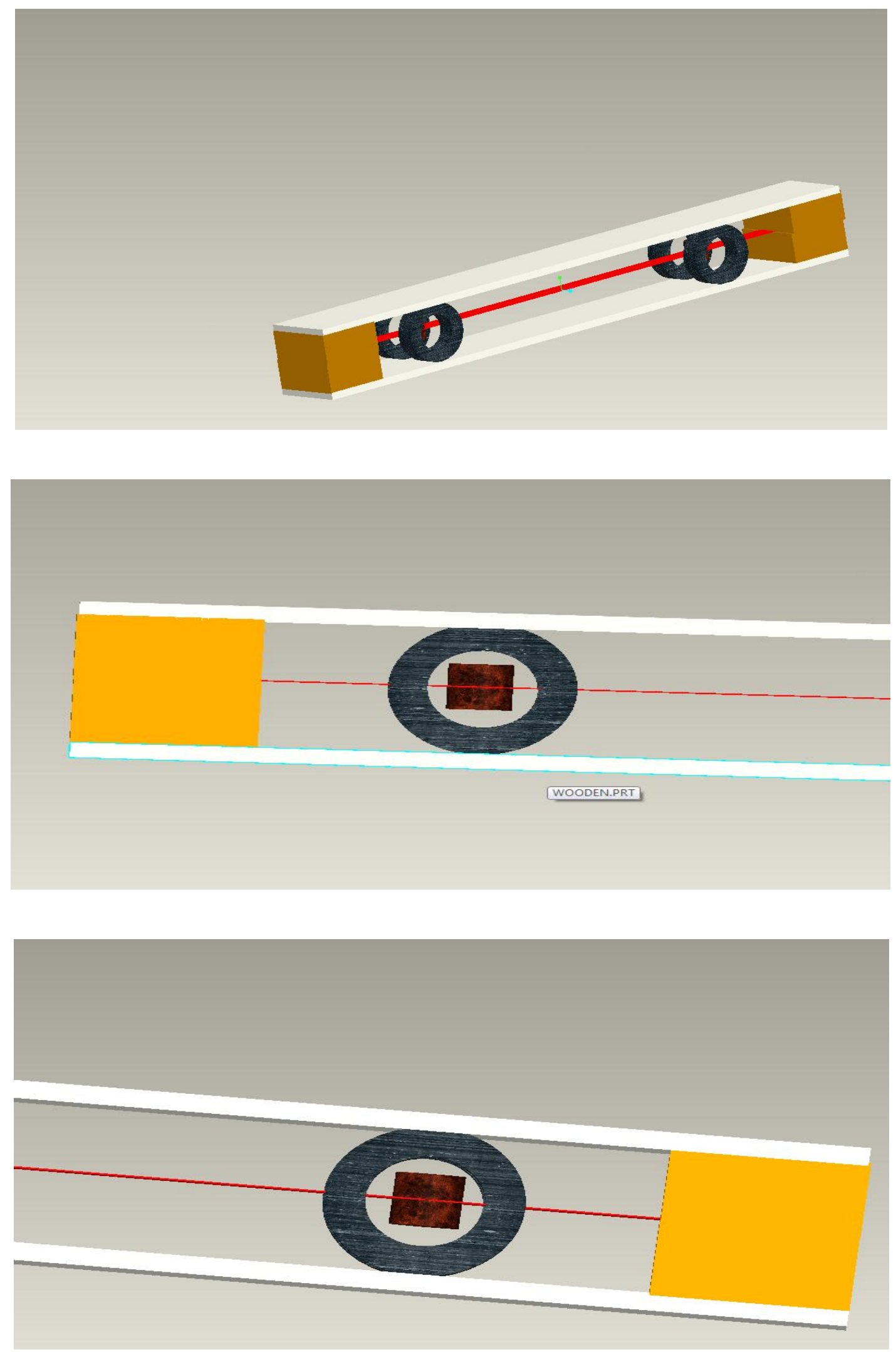


\section{COST ANALYSIS ON THE BASIS OF} THEORETICAL RESULT

Table 2 showing the prices of electricity for household, industry and agriculture uses

\begin{tabular}{|c|c|c|c|}
\hline Use & $\begin{array}{c}\text { Average } \\
\text { price } \\
\text { Rupees/kwH }\end{array}$ & $\begin{array}{c}\text { Reference } \\
\text { price }\end{array}$ & $\begin{array}{c}\text { Rate of } \\
\text { subsidy } \\
\%\end{array}$ \\
\hline household & 6 & 15 & 57.9 \\
\hline Industry & 15 & 15 & NA \\
\hline agriculture & 1.05 & 15 & 93 \\
\hline
\end{tabular}

Based on the experimental data the return on investment on the small scale generation by generation by harnessing the wind energy is zero as it does not produce large amount of electricity. It is expected that a comparably sized of generator of $1 \mathrm{~m}$ size can produced the power output of 5 watt when operable.

Furthermore the design should be able to produce on large scale for approximately 350 rupees per unit plus an additional cost of rupees 50 for maintenance cost for 20 years.

Let us suppose that if we are using 160 watt of electricity every day and we are using it 365 days of electricity every year that is

$$
=365 \times 160=58400 \text { watt }
$$

And each 100 watt of electricity cost rupees 15 by including the subsidy given by the government the subsidy table is as shown above

$$
100 \text { watt will cost }=1.5 \text { rupees }
$$

Then,

$$
365 \times 160=58400 \text { watt per year }
$$

Cost of 58400 watt will be,

$$
=584 \times 1.5=876 \text { rupees per year }
$$

For 20 years it will be

$$
=20 \times 876=17520 \text { rupees }
$$

Now if we are using the small scale generator by harnessing wind energy and each generator generating nearly 5 watt then We will require such 32 small scale generator so that

$$
=32 \times 5=160 \mathrm{watt}
$$

So we have mention cost of one small scale generator is 350

$$
=32 \times 350=11200 \text { rupees }
$$

And 50 rupees maintenance cost so for 20 years maintenance cost will be 1000 rupees

Hence total cost will be sum of $11200+1000=12200$ rupees Hence for 32 small scale generator cost of generation will be 12200 rupees for 20 years of life span.

Hence

cost for 160 watt of electricity $=\frac{12200}{365 \times 20}=$ 1.67 rupees approximately

$$
\begin{gathered}
=\frac{1000}{160}=6.25 \\
=6.25 \times 1.67=10.43 \text { rupees }
\end{gathered}
$$

Thus for 1000 watt the cost in rupees will be 10.43 rupees per kilo watt hour

Table 3 showing cost comparison of the power generated per kilo watt hour.

\begin{tabular}{|c|c|}
\hline Electricity from & $\begin{array}{c}\text { Cost in rupees } \\
\text { per } \mathrm{kWh}\end{array}$ \\
\hline Solar power generator & 15 \\
\hline $\begin{array}{c}\text { Small scale generator } \\
\text { harnessing wind energy }\end{array}$ & 10.43 \\
\hline Thermal power & 17.07 \\
\hline
\end{tabular}

The above table shows cost in rupees per kilo watt hour of the small scale generator harnessing wind energy and compared with the solar and thermal power generation. This shows that electricity generated at cheaper cost with small scale generator harnessing the wind energy.

\section{EXPERIMENTATION AND TESTING}

To test the prototype we use the three speed fan which provides a constant supply of wind power coupled with a multimeter to observe the output voltage. We noted small scale generator having its video tape as membrane subjected to flutter during all three wind speed and capable of working in wide range of wind speed. And with low to medium strength magnet 
Table 4 shows test conducted on normal magnet and high strength egg shaped magnet

\begin{tabular}{|c|c|c|}
\hline $\begin{array}{c}\text { Wind speed } \\
\text { fan setting }\end{array}$ & $\begin{array}{c}\text { Output voltage } \\
\text { with normal } \\
\text { magnet }\end{array}$ & $\begin{array}{c}\text { Output voltage } \\
\text { with egg } \\
\text { shaped magnet }\end{array}$ \\
\hline Low & 0.01 & 0.02 volts \\
\hline Medium & 0.03 & 0.7 volts \\
\hline high & 0.08 & 0.9 volts \\
\hline
\end{tabular}

Table 5 calculation of wind speed using anemometer with the help of fan

\begin{tabular}{|c|c|}
\hline $\begin{array}{c}\text { Distance travelled on } \\
\text { scale for } 60 \mathrm{sec}\end{array}$ & Speed $\mathrm{m} / \mathrm{s}$ \\
\hline 272 & 4.53 \\
\hline 275 & 4.58 \\
\hline 269 & 4.48 \\
\hline 290 & 4.83 \\
\hline 284 & 4.73 \\
\hline
\end{tabular}

The average wind speed from table $=4.63 \mathrm{~m} / \mathrm{s}$

\subsection{Design Consideration}

Tension in belt $=1.5 \mathrm{~N}$

Density of video tape $=1100 \mathrm{~kg} / \mathrm{m}^{3}$

Dimension $=1 \mathrm{~m} \times 2 \mathrm{~cm} \times 1 \mathrm{~mm}$

Velocity of the belt $=\sqrt{\frac{T}{\rho}}$

$$
\begin{gathered}
=\sqrt{\frac{1.5}{1100 \times 1 \times 10^{-2} \times 1 \times 10^{-3}}} \\
=8.25 \mathrm{~m} / \mathrm{s}
\end{gathered}
$$

Power from the wind $=$ pressure fore $x$ area of belt Power from wind coming into the system

$\mathrm{P}=\mathrm{F} \times \mathrm{V}$

$$
\begin{gathered}
=0.5 \times \rho_{\text {air }} \times V_{\text {wind }}^{2} \times C_{d} \times w_{\text {belt }} \times l_{\text {belt }} \\
=0.5 \times 1.23 \times 4.63^{2} \times 0.625 \times 2 \times 10^{-2} \times 1 \\
=0.164 \mathrm{~N}
\end{gathered}
$$

Power from wind coming into the system $=$ force $\times$ velocity

$$
\begin{gathered}
=0.164 \times 8.25 \\
=1.353 \mathrm{watt}
\end{gathered}
$$

From table it is observe that the there is direct connection to the magnetic field strength and the induced voltage. The much stronger magnet immediately improved the performance of small scale generator harnessing wind energy.

Calculation of wind speed using anemometer in front of the table fan

Power from mechanical system, KE=

$$
\begin{gathered}
=\frac{1}{2} \times m_{\text {membrane }} \times v_{\text {membrane }}{ }^{2}+\frac{1}{2} \times m_{\text {magnet }} \times v_{\text {magnet }}{ }^{2} \\
=\frac{1}{2} \times 5 \times v_{\text {membrane }}{ }^{2}+\frac{1}{2} \times 30 \times v_{\text {magnet }}{ }^{2} \\
=\frac{1}{2} \times(5+30) 10^{-3} \times 8.25 \times 8.25 \\
=1.19 \text { Joule }
\end{gathered}
$$

Now frequency of oscillation

$$
\begin{gathered}
=\frac{n}{2 l} \times \text { velocity of belt } \\
n=\text { no of nodes, } l=\text { length of belt } \\
=\frac{1}{2 \times 1} \times 8.25 \\
=2.0625 \mathrm{~Hz}
\end{gathered}
$$

Now power,

$$
\begin{gathered}
=\frac{K \cdot E}{t}=\frac{1.191}{2 \times 2.0625} \\
=0.2887 \text { watt }
\end{gathered}
$$

Efficiency of wind power that is converted into mechanical energy

$$
\begin{gathered}
=\frac{\text { power from mechanical system }}{\text { power from wind coming into system }} \\
=\frac{0.2887}{1.353} \\
=0.2133
\end{gathered}
$$

\subsection{Results and Discussion}

Table 6 showing statistical value of output voltage obtained at different fan speed

\begin{tabular}{|c|c|c|}
\hline Sr no & $\begin{array}{c}\text { Average wind } \\
\text { speed }\end{array}$ & $\begin{array}{c}\text { Output } \\
\text { obtained }\end{array}$ \\
\hline 1 & $3 \mathrm{~m} / \mathrm{s}$ & 0.01 volts \\
\hline 2 & $4 \mathrm{~m} / \mathrm{s}$ & 0.04 volts \\
\hline 3 & $5 \mathrm{~m} / \mathrm{s}$ & 0.09 volts \\
\hline
\end{tabular}




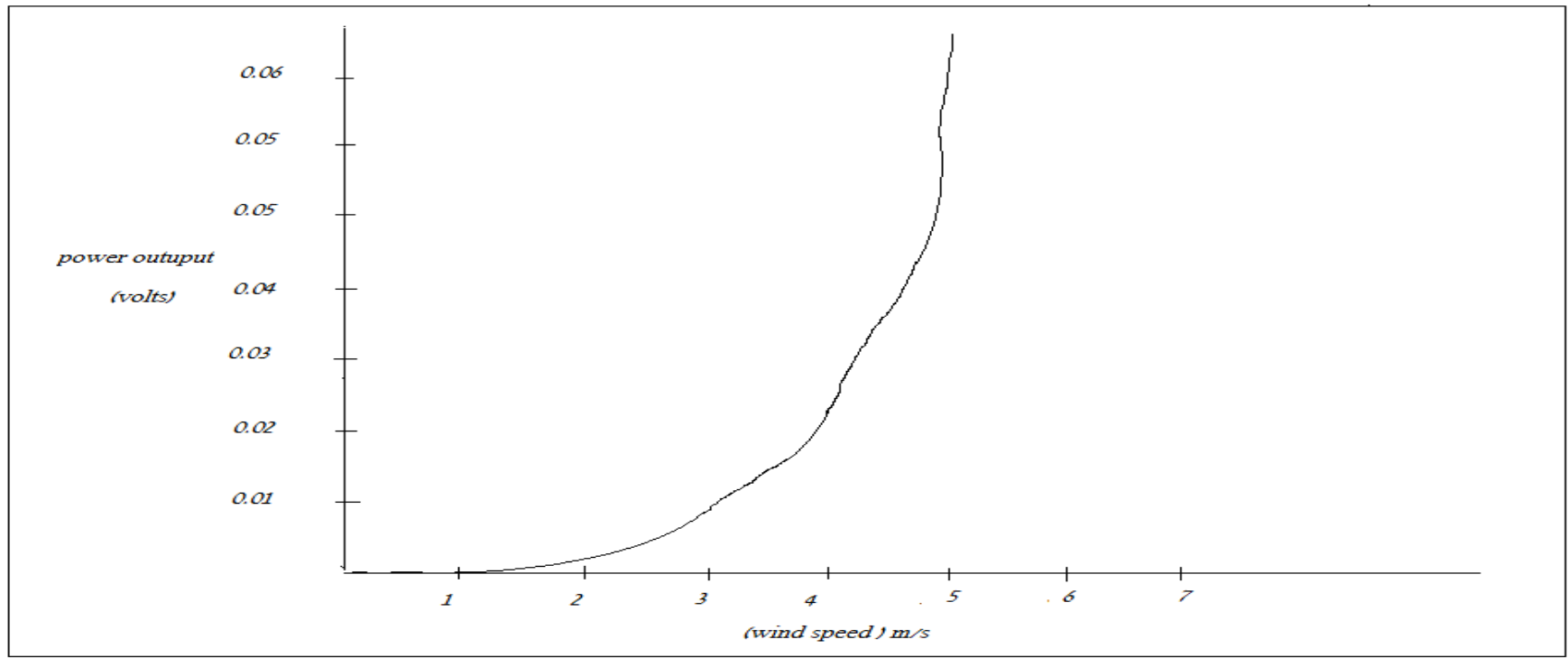

Fig 5.1 shows the wind speed verses the power output in volts.

\subsection{Future Scope}

- More research and development is required in case of small scale generator harnessing the wind energy so as to get more power output.

- It would be alternative source of power for electricity generation for house hold pupose where the electricity requirement is less as in case of remote areas where sufficient amount of wind is available throughout the year.

- As the electricity generation is on cost per watt basis it is cheaper source of power for electricity generation.

\section{GLOSSARY OF TERMS}

A/C Current - In alternating current the flow of electric charge periodically reverses direction. An electric charge would for instance move forward, then backward, and repeat this movement indefinitely. This can be represented accurately by a sine wave.

D/C Current - Direct current (DC) is the unidirectional flow of electric charge. Direct current may flow in a conductor such as a wire, but can also be through semiconductors, insulators, or even through a vacuum as in electron or ion beams. The electric charge flows in a constant direction, distinguishing it from alternating current (AC).

Rectifier - A rectifier is an electrical device that converts alternating current (AC) to direct current (DC), this conversion is known as rectification. Rectifiers can be used in components of power supplies and as radio signal detectors. A device which performs the opposite function (converting DC to AC) is known as an inverter.
Aero elastic Flutter - A self-feeding vibration where aerodynamic forces on an object couple with a structure's natural mode of vibration to produce rapid periodic motion.

Electromotive Force (emf) - electromotive force is "that which tends to cause current (actual electrons and ions) to flow." An example of such a force is that created by a vibrating or rotating magnet in close proximity to a copper wire.

\section{REFERENCES}

[1] Shawn Frayne 'Windbelt generator' 'Humdinger Wind Energy' Energy harvesting and storage journal 17 July 2009. http://www.humdingerwind.com.

[2] Ward Logan. 'Windbelt, Cheap Generator Alternative, Set to Power Third World, Popular Mechanics, and November 2007.

[3] Borz Meghan, "Lighting an African School with Alternative Energy"; Rutgers School of Engineering, 2009.

[4] Shawn Frayne Windbelt Innovation: Medium windbelt; Humdinger Wind Energy, February 12, 2010

[5] Gunter Pauli ,"Wind Energy without Turbines" The Blue Economy 2010

[6] Matt Schelke ,Wind Energy with Windbelt Generator Technology Article by Matt Schelke Edited \& published by Whitney Worden on Jul 23, 2010

[7] An electromagnetic energy scavenger from direct air flow Preston Galle1, Florian Herrault1 November 9-12, (2008)

[8] Feasibility of small scale urban energy generation Mark A. Moriarty, University of Pittsburgh July 31, 2009

[9] Power Generation from Aero elastic Flutter at Low Reynolds Number Design, Fabrication and Analysis of 
a Wind Belt System Geoff Johnson, Lucas Hartman, Tejus Goenka

[10] Renewable energy for Africa, Mallika Nair, institute of environmental securities, may 2009.

[11] "Harnessing Wind Energy to Power Homes in Tonle Sap" Gone With the Wind Sophie Thompson, 2009.

[12] Wind energy harvester from humdinger, "Energy harvesting journal”, Raghu Das, 26 May 2010.

[13] C. D. Richards, M. J. Anderson, D. F. Bahr, and R. F. Richards, "Efficiency of energy conversion for devices containing a piezoelectric component," Journal of Micromechanics and Micro engineering, vol. 14, no. 5, pp. 717-721, 2004.

[14] S. P. Beeby, M. J. Tudor, and N. M. White, "Energy harvesting vibration sources for Microsystems applications," Measurement Science and Technology, vol. 17, no. 12, pp. R175-R195, 2006.

[15] Anton, R. Steven, Sodano, and A. Henry, "A review of power harvesting using piezoelectric materials (20032006)," Smart Materials and Structures, vol. 16, no. 3, pp. R1-R21, June 2007.

[16] M. Isogai, K. Yamasaki, Matsubara, M., and Asaoka, T., "Design Study of Elastically Supported Flapping Wind Power Generator," International Forum on Aeroelasticity and Structural Dynamics, Amsterdam, 2003.

[17] J. A. Paradiso and T. Starner, "Energy scavenging for mobile and wireless electronics," Pervasive Computing, IEEE, vol. 4, no. 1, pp. 18-27, 2005.

[18] R. J. M. Vullers, R. Van Schaijk, C.Van Hoof, R. Mertens, "Micro power energy harvesting," Solid-State Electronics, vol. 53, Issue 7, pp. 684-693, July 2009.

[19] R. H. Scanlan, "The Action of Flexible Bridges under Wind, I: Flutter Theory," Journal of Sound and Vibration, vol. 60(2), pp. 187-199, 1978. 